\title{
Ripper for processing slope fields
}

\author{
Berdirasul Khudayarov ${ }^{1}$, Sherzod Mardonov ${ }^{2}$, Nurbek Rashidov ${ }^{3}$, Xasan Sodikov $^{3}$ and \\ Dilshod Baratov ${ }^{4 *}$ \\ ${ }^{1}$ Tashkent Institute of Irrigation and Agricultural Mechanization Engineers, Tashkent, Uzbekistan \\ ${ }^{2}$ Beshkent Agricultural Technical School under the Tashkent Institute of Irrigation and Agricultural \\ Mechanization Engineers, Karshi, Uzbekistan \\ ${ }^{3}$ Karshi Engineering Economic Institute, Karshi, Uzbekistan \\ ${ }^{4}$ Karshi branch of Tashkent Institute of Irrigation and Agricultural Mechanization Engineers, Karshi, \\ Uzbekistan
}

\begin{abstract}
The purpose of the study is to substantiate the parameters of a spherical disk working body. New technology of tillage of slope fields that prevent water erosion, a design scheme of a ripper for its implementation is presented. The ripper consists of lower and upper working bodies of the "paraglider" type and a spherical disk. The study applied the laws and rules of theoretical mechanics, agricultural mechanics, mathematical statistics, and methods of strain measurement and the methods given in the existing regulatory documents (TSt 63.04.2001, TSt 63.03.2001). The new technology of tillage of slope fields makes it possible to form step ridges on the surface of the arable land and on the bottom of the furrow, which protects the soil of the slopes from water erosion. It is established that when the diameter of the spherical disk of $510 \mathrm{~mm}$, the curvature radius of $56 \mathrm{~mm}$, tilt angle relative to the direction of motion of $28-30^{\circ}$ to the vertical at an angle of $17-18^{\circ}$, the transverse and longitudinal distance between the disc and work on the bottom ripper respectively 30 and $20 \mathrm{~cm}$ ensures the formation of ridges on the surface of the field according to agrotechnical requirements at a minimum cost of energy.
\end{abstract}

\section{Introduction}

Currently, the leading position is occupied by developing and implementing energy - and resource-saving, and highly efficient machines for tillage. If we consider that " $31 \%$ of the land is subject to water erosion, and $34 \%$ to wind erosion, and annually more than 60 billion tons "tons of fertile soil is washed into the world ocean" [5-6, 9, 17, 24-25, 27-30], then the development of energy - and resource-saving machines and tools that protect the soil from wind and water erosion is considered an important task.

In the world, research works are being conducted aimed at developing soil protection technologies for protecting the soil from wind and water erosion and technical means for their implementation [32-33]. It is relevant to conduct targeted scientific research on the development of dump and non-dump anti-erosion working bodies, ensuring resource

* Corresponding author: sh.doniyorbek@mail.ru 
conservation in the processes of their interaction with the soil.

Research on the development and application of machinery to protect the soil from water and wind erosion, in particular machinery working bodies of the "paraplu", studying their performance and justification of the parameters studied F.Mamatov [1-23], B.Mirzayev [412, 14-23] V.Alexandrian [28], A.Vagin [29], N.N.Nagorny [30], V.Svetlichniy [30], V.M.Drinca [32], D.A.Tryapitsyn [34], Pazova T [33], B.Borisenko [32] and others.

The machines and tools created as a result of these studies are used with certain positive results in the tillage of the slopes. However, these studies have not sufficiently studied the issues of substantiating the parameters of the disk working bodies of rippers that form ridges on the surface of the field to protect the soil from water erosion and ensure high quality of work with minimal energy costs [38-39].

The purpose of the study is to substantiate the parameters of a spherical disk working body.

\section{Methods}

The study applied the laws and rules of theoretical mechanics, agricultural mechanics, mathematical statistics, and methods of strain measurement and the methods given in the existing regulatory documents (TSt 63.04.2001, TSt 63.03.2001).

Analysis of studies has shown that the prevention of water erosion and increasing the degree of soil crumbling, as well as reducing fuel consumption, labor, and other costs when processing slope fields, can be achieved by using a ripper that forms ridges on the surface of the arable land and at the bottom of the furrow.

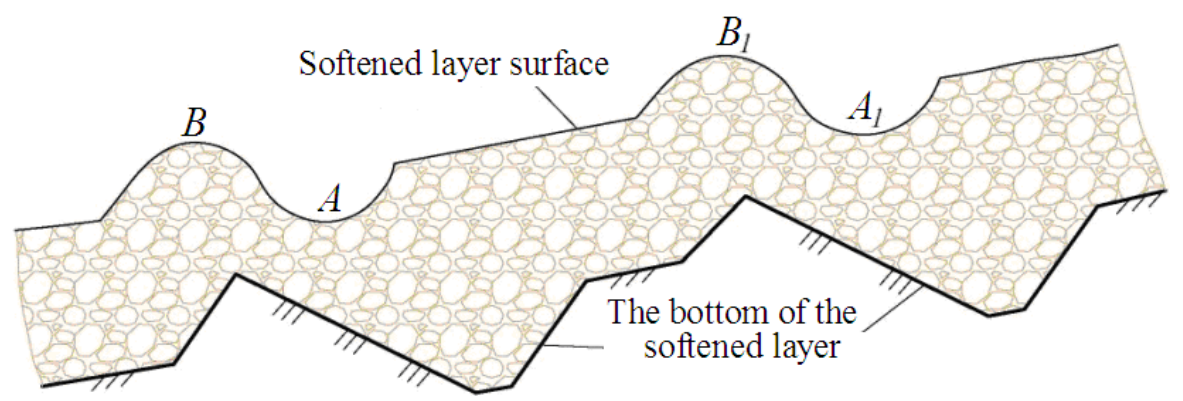

Fig. 1. Scheme of soil loosening technology and formation of ridges on slope fields: $A, B, A_{1}, B_{1}$ are grooves and ridges, respectively

The loosening of the soil and the formation of ridges are carried out on inclined fields simultaneously (Fig.1). The technology is carried out as follows: at first, the soil of the slope field is loosened in the form of steps without a fall. In this case, the bottom of the furrow of the loosened layer looks like in Fig.1. On the surface of the loosened layer, ridges $\mathrm{B}, \mathrm{B}$ are formed due to the formation of grooves A, Ot. In this case, rain precipitation is absorbed into the loosened layer. Due to the different heights of the steps, the soil water does not flow down the slope. 


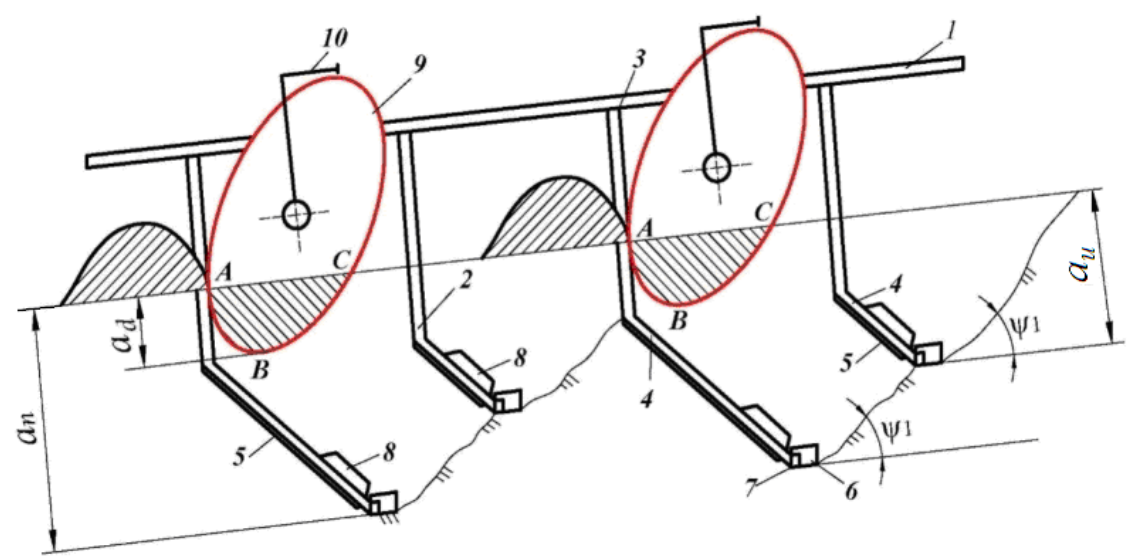

Fig. 2. Technological process of the ripper equipped with spherical disks: 1 is frame; 2,3 are lower and upper rippers with an inclined rack; 4 are inclined ripper racks; 5 is knife; 6 are chisels; 7 is field board; 8 is plate; 9 is spherical disk; 10 is turning lever

A ripper scheme has been developed to implement the above technology, equipped with lower and upper ripping working bodies of the "paraglau" type and a spherical disk (Fig. 2). The slope of slope fields in the Republic, especially in the Kashkadarya region, is $3-12^{\circ}$. At the same time, the protection of the slope soil from water erosion depends on the parameters of the ridge

The ridge parameters, in addition to the slope of the field, depending on the amount of precipitation, their duration, and variety. In this regard, in the autumn months of 2017 2018 , ridges of various cross-sectional areas and sizes were formed on the slope fields with the help of hand tools. These ridges were preserved in their natural form until the sowing works. Based on these studies, it was found that the cross-sectional area of the ridge is at least $97.5 \mathrm{~cm}^{2}$.

The technological process of forming ridges in the direction of the slope of the slopes of agricultural fields according to agrotechnical requirements can be carried out by cutting out a layer of a certain cross-section and turning it in the direction of the slope.

For the formation of ridges and furrows on the surface of the arable land, a working body of the spherical disk type is selected. It is equipped with a turning mechanism. The spherical disk rotation mechanism parameters include the length of the handle $O A=R$, the length of the slot in the lever ln, and the length of the hydraulic cylinder rod AA2 (Fig 3). 


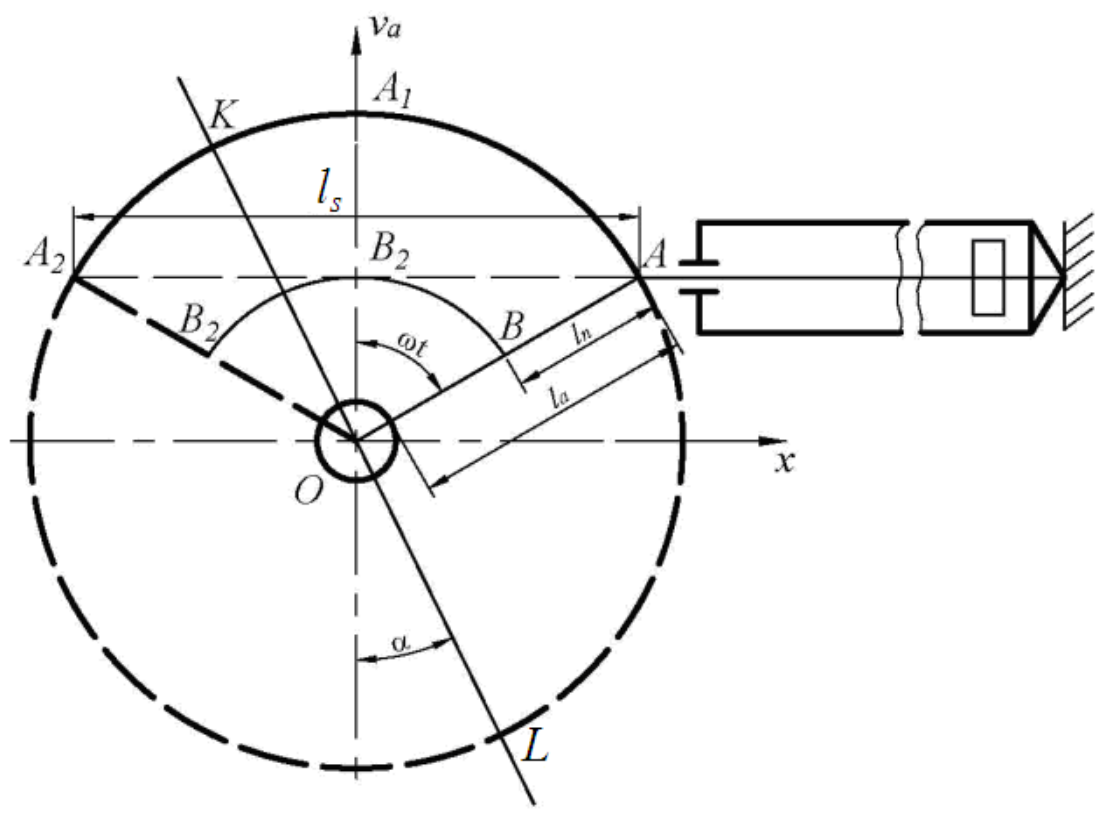

Fig. 3. Scheme for determining the parameters of the rotary mechanism

Considering that the disk rack is installed on the side of its working surface and the design features of attaching the rack to the frame, the length of the lever $\mathrm{R}$ is assumed to be 130 $\mathrm{mm}$.

To move the spherical disk from the working position of the CL to the next one-A2, the lever must turn to position A1. From Fig. 3, the length of the AB slot in the lever is determined by the following expression

$$
A B=R-R \cos \omega_{t}=R\left(1-\cos \omega_{t}\right) \text {. }
$$

Given that to move the lever to the final position of $O A_{2}$, it must rotate at an angle of $t=50^{\circ}$ $60^{\circ}$ and $R=130 \mathrm{~mm}$, we find $A B=65 \mathrm{~mm}$. The length of the rod is determined from the triangle $O A B$ : $l_{s}=2 A B \quad l=224 \mathrm{~mm}$. To implement the working process of this mechanism, a hydraulic cylinder $C-40$ was selected; its piston stroke is $250 \mathrm{~mm}$.

The width of the formed ridge depends on the distance of the spherical disk throwing the soil particles in the transverse direction. The distance of the discarding of soil particles by a spherical disk is found by the following formula

$$
X_{y}=\frac{v_{a} \cos (\alpha+\xi) \cdot\left[v_{a} \sin (\alpha+\xi)+\sqrt{v_{a}^{2} \sin (\alpha+\xi)+2 g h_{n}}\right]}{g}
$$

where, $v_{a}$ is the absolute velocity of the soil particles thrown by the spherical disk, $\mathrm{m} / \mathrm{s} ; a$ is the angle of the spherical disk to the direction of movement of the unit, degree; $h_{n}$ is the difference of the horizontal planes formed by furrows and ridges based on the slope of the field, m. $\xi$ is the central angle of the arc of the spherical disk, degree; $g$ is the acceleration of gravity, $\mathrm{m} / \mathrm{s}^{2}$.

The range of transverse rejection of soil particles by a spherical disk can be determined by the following expression (Figure 4). 


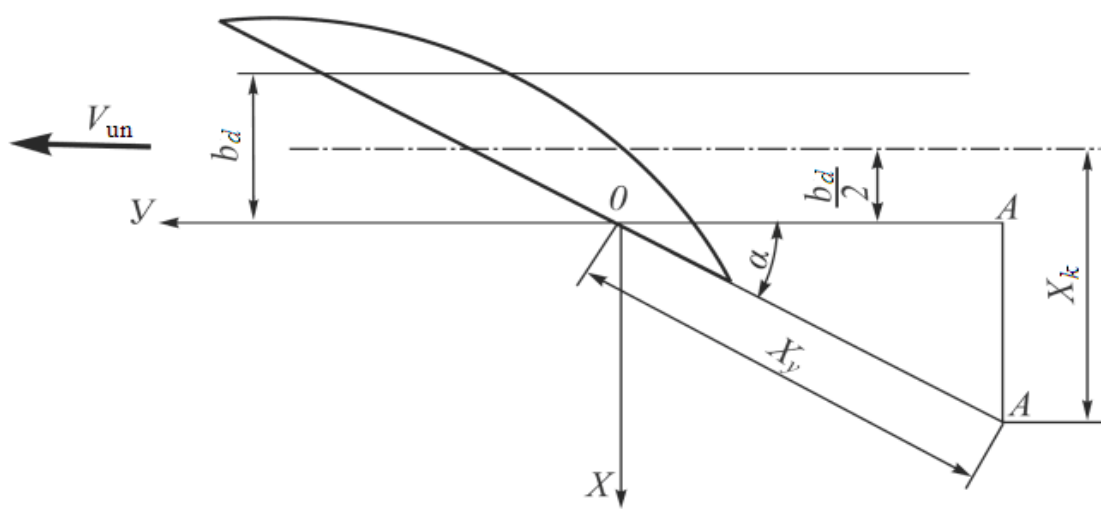

Fig. 4. Scheme for determining the range of transverse discarding of soil by a spherical disk

$$
X_{k}=\left\{\frac{v_{a} \cos (\alpha+\xi)\left[v_{a} \sin (\alpha+\xi)+\sqrt{v_{a}^{2} \sin (\alpha+\xi)+2 g h_{n}}\right]}{g}\right\} \sin \alpha+\frac{b_{d}}{2},
$$

From (3), we see that the range of cross drop of soil particles $H_{c}$ depends on the absolute velocity of a spherical disc, the angle of incidence of the soil, slope fields, and the width of the disk.

Figure 5 shows graphs of the dependence of the cross-drop distance of the soil on the absolute velocity $V_{a}$ and the angle of installation of the disk.

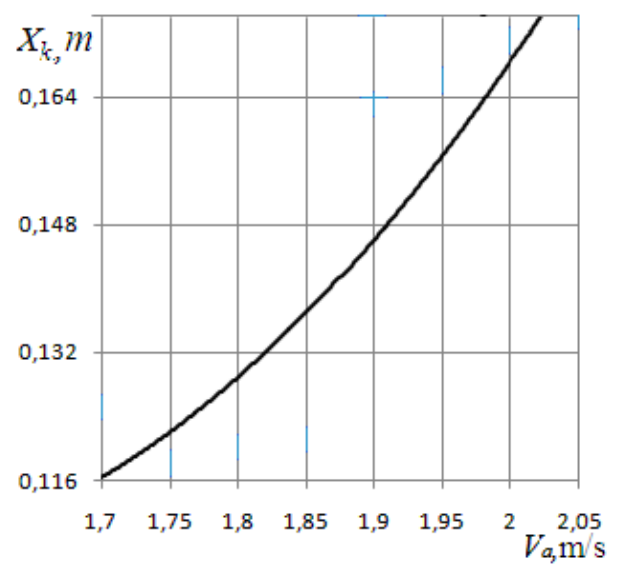

a) $\alpha=28^{\circ} ; h_{n}=0,01 \mathrm{~m}$

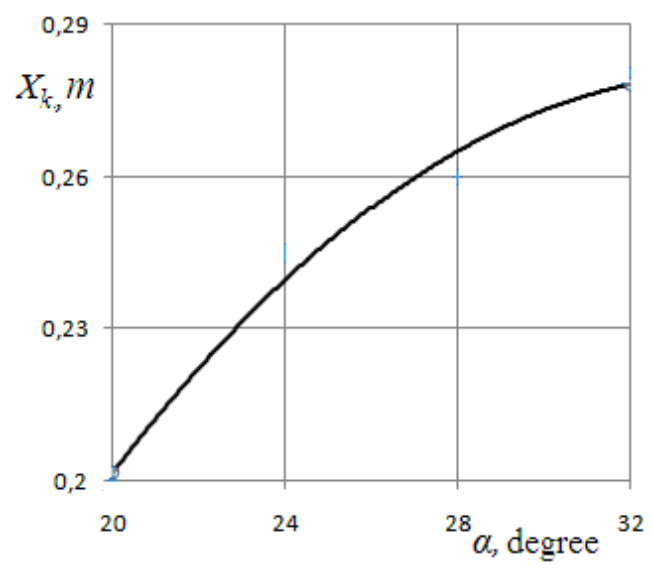

b) $V_{a}=2,0 \mathrm{~m} / \mathrm{s} ; h_{n}=0,01 \mathrm{~m}$

Fig. 5. Graphs of changes in $H_{c}$ as a function of $V_{a}, \alpha$, and $h_{p}$

The graphs analysis shows that to place the discarded soil particles along the axis of the formed ridge, the speed of movement of the spherical disk should be 1,75-25,05 m/s, and the installation angle should be within $28-30^{\circ}$.

The minimum transverse distance from the post of the lower ripper to the spherical disk was determined taking into account the zone of soil deformation of the bit of the upper ripper: 


$$
L_{k p} \geq b_{k i}+b_{i}+a_{i} \operatorname{ctg} \psi_{1}-b_{k}+\sqrt{R^{2}-\left(R-a_{d}\right)^{2}} \sin \alpha
$$

The calculations performed by expression (4) at $b_{k}=35 \mathrm{~cm}, b_{k}=10 \mathrm{~cm}, b_{i}=6 \mathrm{~cm}, \psi_{1}=45^{\circ}$, $R=25,5 \mathrm{~cm}, a_{i}=25 \mathrm{~cm}$, and $a_{d}=12 \mathrm{~cm}$ showed that at a transverse distance between the lower ripper stand and the spherical disk of at least $18 \mathrm{~cm}$, their clogging with soil is excluded.

According to Fig.7, the longitudinal distance from the spherical disk to the lower ripper rack is determined by the following expression:

$$
L_{b p} \geq \frac{2 \cdot\left[b_{k p}+b_{i}+a_{i} \operatorname{ctg} \psi_{1}-b_{k}+\sqrt{R^{2}-\left(R-a_{d}\right)^{2}} \sin \alpha\right]-t_{t}}{2 \cos (\alpha+\varphi)},
$$

where $\mathrm{tt}$ is the thickness of the ripper stand, $\mathrm{cm}$;

According to the formula (5), for $L_{b p}=20-26 \mathrm{~cm}, t_{t}=5 \mathrm{~cm}, \alpha=30^{\circ} i_{f}=30^{\circ}$, the longitudinal distance between the lower ripper stand and the spherical disk should be at least $26 \mathrm{~cm}$.

The minimum longitudinal distance from the upper ripper to the spherical disk is determined from the condition that the soil deformation zone treated with the upper ripper bit does not reach the structural elements of the spherical disk:

$$
L_{b i} \geq b_{t}+H_{k t} \sin \beta_{b}+l_{i} \cos \alpha_{i}+a_{i} \operatorname{ctg} \psi+\sqrt{R^{2}-\left(R-a_{d}\right)^{2}} \cos \alpha
$$

where $b_{t}$ is width stone burner ripper, $\mathrm{cm} ; N_{k t}$ is the slant height of the rack, $\mathrm{cm} ; l_{i}$ are length drill bits, $\mathrm{cm} ; \psi$ is the angle of shearing the soil in the longitudinal direction, degree.

Calculations carried out according to expression (6) at $b_{t}=200 \mathrm{~mm}, a_{i}=65^{\circ}, \varphi=30^{\circ}$, $N_{k m}=0,20 \mathrm{~m}, \beta_{b}=25^{\circ}$ showed that the longitudinal distance between the upper ripper rack and the spherical disk should be at least $33 \mathrm{~cm}$.

\section{Results and Discussion}

In experimental research studied the effect of the scheme relative position of the working bodies on the frame, the transverse and longitudinal distances between the spherical disk and lowered the working body, parameters spherical disk, and the operating speed of the traction resistance of the cultivator, the degree of cracking of the soil and the height of the ridge, and in the second stage was conducted multivariate experiments with the use of mathematical planning of experiments.

According to the data of the conducted one-factor experiments, it was found that at speeds of $6-9 \mathrm{~km} / \mathrm{h}$ to ensure the required quality of work and the height of the ridge with minimal energy consumption, the spherical disk should be installed at an angle of $28-30^{\circ}$ to the direction of movement, the transverse and longitudinal distance between the disk and the lower ripper should be 30 and $20 \mathrm{~cm}$, respectively. 


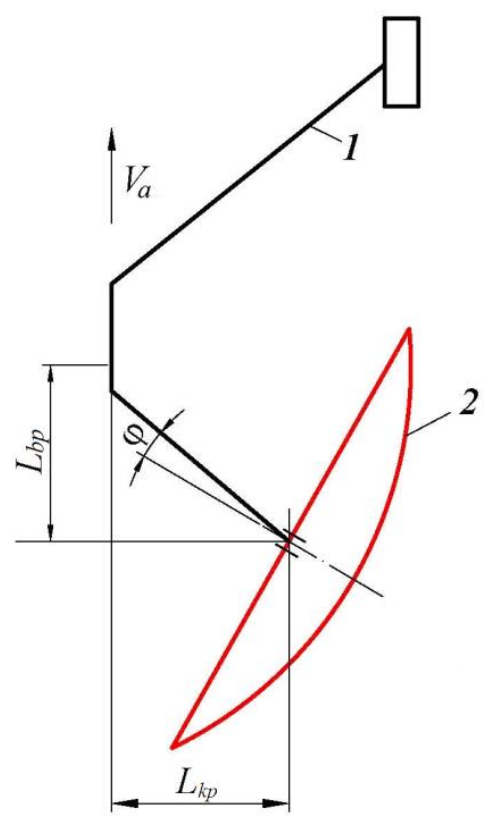

Fig. 6. Scheme for determining the longitudinal distance between the spherical disk and the lower ripper rack: 1 is the lower ripper; 2 is the spherical disk

According to the results obtained at speeds of $6-9 \mathrm{~km} / \mathrm{h}$ to ensure the required quality of work with minimal energy consumption, the angle of installation of the spherical disk to the direction of movement should be within $28-30^{\circ}$ and the transverse distance between the lower ripper and the spherical disk $18-20 \mathrm{~cm}$. These results correspond to the results of theoretical studies.

\section{Conclusions}

1. The new technology of tillage of slope fields makes it possible to form step ridges on the surface of the arable land and the furrow's bottom.

2. The ripper's most optimal design scheme is considered a scheme consisting of upper and lower working bodies with inclined posts of the "paraglider" type and a ridge shaper of the spherical disk type.

3. With a diameter of a spherical disk of $510 \mathrm{~mm}$, a radius of curvature of $56 \mathrm{~mm}$, an angle of installation relative to the direction of movement of $28-30^{\circ}$, and to the vertical at an angle of $17-18^{\circ}$, the formation of ridges on the surface of the field is ensured following agricultural requirements with minimal energy consumption.

4. At the transverse and longitudinal distance between the disc working body and the lower ripper, respectively, 30 and $20 \mathrm{~cm}$, the width and length of the field board, respectively, 7 and $18 \mathrm{~cm}$, clogging of the working bodies with plant residues is excluded, high-quality loosening of the soil and stable movement of the ripper are ensured. 


\section{References}

1. Mamatov, F.M., Eshdavlatov, E., Suyunov, A. The Shape of the Mixing Chamber of the Continuous Mixer // Jour of Adv Research in Dynamical \& Control Systems, Vol. 12, 07-Special Issue, (2020). DOI: 10.5373/JARDCS/V12SP7/20202318 ISSN 1943$023 \mathrm{X}$.

2. Mamatov, F., Ergashev, I., Ochilov, S., Pardaev, X. Traction Resistance of Soil Submersibility Type "Paraplau" // Jour of Adv Research in Dynamical \& Control Systems, Vol.12, 07-Special Issue, (2020). DOI: 10.5373/JARDCS/V12SP7/20202336 ISSN1943-023X.

3. Aldoshin, N., Mamatov, F., Ismailov, I., Ergashov, G. Development of combined tillage tool for melon cultivation // 19th international scientific conference engineering for rural development Proceedings, Jelgava, 20. (2020). Volume 19. ISSN 1691-5976. DOI:10.22616/ERDev.2020.19.TF175.

4. Umurzakov, U., Mirzaev, B., Mamatov, F., Ravshanov, H., Kurbonov, S. A rationale of broach-plow's parameters of the ridge-stepped ploughing of slopes // XII International Scientific Conference on Agricultural Machinery Industry IOP Conf. Series: Earth and Environmental Science 403(2019) 012163 IOP Publishing doi:10.1088/1755-1315/403/1/012163.

5. Mirzaev, B., Mamatov, F., Chuyanov, D., Ravshanov, X., Shodmonov, G., Tavashov, R and Fayzullayev, X. Combined machine for preparing soil for cropping of melons and gourds // XII International Scientific Conference on Agricultural Machinery Industry. doi.org/10.1088/1755-1315/403/1/012158.

6. Mirzaev, B., Mamatov, F., Ergashev, I., Ravshanov, H., Mirzaxodjaev, Sh., Kurbanov, Sh., Kodirov, U and Ergashev, G. Effect of fragmentation and pacing at spot ploughing on dry soils // E3S Web of Conferences 97. doi.org/10.1051/e3sconf/201913501065.

7. Mamatov, F., Mirzaev, B., Shoumarova, M., Berdimuratov, P., Khodzhaev, D. Comb former parameters for a cotton seeder// International Journal of Engineering and Advanced Technology (IJEAT) Volume-9 Issue1 October/ DOI: 10.35940/ijeat.A2932.109119.

8. Mamatov, F., Mirzaev, B., Batirov, Z., Toshtemirov, S., Tursunov, O., Bobojonov, L. Justification of machine parameters for ridge forming with simultaneous application of fertilizers // CONMECHYDRO - 2020 IOP Conf. Series: Materials Science and Engineering 883(2020) 012165 IOP Publishing. doi:10.1088/1757899X/883/1/012165.

9. Mirzaev, B., Mamatov, F., Avazov, I., Mardonov, S. Technologies and technical means for anti-erosion differentiated soil treatment system // E3S Web of Conferences. doi.org/10.1051/e3sconf/20199705036.

10. Aldoshin, N., Didmanidze, O., Mirzayev, B., Mamatov, F. Harvesting of mixed crops by axial rotary combines // Proceeding of $7^{\text {th }}$ International Conference on Trends in Agricultural Engineering 2019. $17^{\text {th }}-20^{\text {th }}$ Prague, Czech Republic. - pp.20-26. September (2019).

11. Mirzaev, B., Mamatov, F., Aldoshin, N and Amonov, M. Anti-erosion two-stage tillage by ripper// Proceeding of 7 th International Conference on Trends in Agricultural Engineering 17th-20th. Prague, Czech Republic. - pp.391-396. September (2019)

12. Mirzaev, B., Mamatov, F., Ergashev, I., Islomov, Yo., Toshtemirov, B., Tursunov O. Restoring degraded rangelands in Uzbekistan // Procedia Environmental Science № 6. - pp 395-404. (2019).

13. Uzakov, Z.U., Mamatov, F.M., Begulov, O. Implementation of object-oriented 
Programming technology in the one-dimensional oil displacement problem // International Conference on information Science and Communications Technologies: ICISCT 2019/0012008. Tashkent, Uzbekistan. INSPEC Accession Number: 19412491. DOI: 10.1109/ICISCT47635.2019.9012008.

14. Mamatov, F., Mirzaev, B., Berdimuratov, P., Turkmenov, Kh., Muratov, L., Eshchanova, G. The stability stroke of cotton seeder moulder // CONMECHYDRO (2020). IOP Conf. Series: Materials Science and Engineering 883 (2020) 012145 IOP Publishing. doi:10.1088/1757-899X/883/1/012145.

15. Mamatov, F., Mirzaev, B., Tursunov, O. A Justification of Broach-Plow's Parameters of the Ridge-Stepped Ploughing // E3S Web of Conferences 97, 05035 (2019). doi.org/10.1051/e3sconf/20199705035.

16. Ahmedov, B.J., Mirzaev, B.S.,Mamatov, F.M., Khodzhaev, D.A., Julliev, M.K. Integrating of gis and gps for ionospheric perturbations in d- And f-layers using vlf receiver // InterCarto, InterGIS 26, - pp. 547-560. DOI: 10.35595/2414-9179-2020-126-547-560.

17. Mamatov, F., Mirzaev, B., Tursunov, O., Ochilov, S and Chorieva, D. Relief, physicomechanical and technological properties of soil in the cotton growing area // ICECAE (2020). IOP Conf. Series: Earth and Environmental Science 614(2020) 012169. IOP Publishing. doi:10.1088/1755-1315/614/1/012169.

18. Shamsutdinov, Z., Ubaydullaev, Sh., Shamsutdinov, N., Mirzaev, B., Mamatov, F., and Chorshabiyev, N. The concept of the phytogenic field: theory, research experience and practical significance // ICECAE 2020. IOP Conf. Series: Earth and Environmental Science 614(2020) 012164. IOP Publishing. doi:10.1088/17551315/614/1/012164.

19. Umurzakov, U., Mamatov, F., Aldoshin, N., and Mirzaev, B. Exploration of tillage technologies in the Republic of Uzbekistan // ICECAE (2020) IOP Conf. Series: Earth and Environmental Science 614(2020) 012168. IOP Publishing. doi:10.1088/17551315/614/1/012168.

20. Mamatov, F., Aldoshin, N., Mirzaev, B., Ravshanov, H., Kurbanov, Sh and Rashidov, N. Development of a frontal plow for smooth, furless plowing with cutoffs // IPICSE 2020. IOP Conf. Series: Materials Science and Engineering 1030 (2021) 012135 IOP Publishing. doi:10.1088/1757-899X/1030/1/012135.

21. Mamatov, F., Mirzaev, B., Mirzahodzhaev, Sh., Uzakov, Z and Choriyeva, D. Development of a front plow with active and passive working bodies // IPICSE (2020). IOP Conf. Series: Materials Science and Engineering 1030 (2021) 012164. IOP Publishing. doi:10.1088/1757-899X/1030/1/012164.

22. Mamato, F.M., Eshdavlatov, E., Suyuno, A. Continuous Feed Mixer Performance //Journal of Advanced Research in Dynamical and Control Systems (JARDCS). Volume-12, 07-Spesia1 Issue, (2020). DOI: 10.5373/JARDCS/V12SP7/20202343. ISSN 1943-023X.

23. Mamatov, F., Ergashev, I., Mirzaev, B., Pardaev, X, Chorieva, D. Research of the Penetration Process of the Frontal Plow // 2nd Bukittinggi International Conference on Education (BICED) (2020). Journal of Physics: Conference Series 1779 (2021) 012002. IOP Publishing. doi:10.1088/1742-6596/1779/1/012002.

24. Kodirov, U., Aldoshin, N., Ubaydullayev, Sh., Sharipov, E., Muqimov, Z and Tulaganov, B. The soil preparation machine for seeding potatoes on comb // CONMECHYDRO - (2020) IOP Conf. Series: Materials Science and Engineering 883(2020) 012143 IOP Publishing doi:10.1088/1757-899X/883/1/012143.

25. Ravshanov, Kh., Fayzullaev, Kh., Ismoilov, I., Irgashev, D., Mamatov, S. The machine for the preparation of the soil in sowing of plow crops under film // CONMECHYDRO - (2020) IOP Conf. Series: Materials Science and Engineering 
883(2020) 012138 IOP Publishing doi:10.1088/1757-899X/883/1/012138.

26. Ravshanov, H, Babajanov, L, Kuziev, Sh, Rashidov, N, Kurbanov, Sh. Plough hitch parameters for smooth tails// CONMECHYDRO - 2020 IOP Conf. Series: Materials Science and Engineering 883(2020) 012139 IOP Publishing doi:10.1088/1757899X/883/1/012139.

27. Chuyanov, D., Shodmonov, G.,Avazov, I., Rashidov, N, Ochilov, S. Soil preparation machine parameters for the cultivation of cucurbitaceous crops // CONMECHYDRO - (2020) IOP Conf. Series: Materials Science and Engineering 883(2020) 012139 IOP Publishing doi:10.1088/1757-899X/883/1/012122.

28. Mamatov F.M., Mirzaev B.S., Avazov I.Zh.. Agrotehnicheskie osnovy sozdanija protivojerozionnyh vlagosberegajushhih tehnicheskih sredstv obrabotki pochvy $\mathrm{v}$ uslovijah Uzbekistana // - Prirodoobustrojstvo, [In Russian]. (2014).

29. Mamatov F.M., Mirzaev B.S. Erosion preventive technology of crested ladder-shaped tillage and plow design // European Applied Sciences. Stuttgart (Germany), - pp. 7173. (2014).

30. Lobachevskij Ja.P., Mamatov F., Jergashev I.T. Frontal'nyj plug dlja hlopkovodstva // - Hlopok, № 6. - 35-37 str. [In Russian]. (1991).

31. Alexandryan K, Gasparyan A, Karakhanyan K Machines for the development of mountain slopes and combat water erosion of soil (Agropromizdat). (1985).

32. Vagin A Mechanization of soil protection from water erosionin the Nonchernozem strip (Kolos). (1977)

33. Nagorniy $\mathrm{N}$ Technologies and means of mechanization for soil protection from erosion on arable slope lands of Ukrainep 34. (1989).

34. Svetlichniy A, Cherniy S, Shvebs G 2004 Erososcience theoretical and applied aspects(ITD University Book)

35. Drincha V, Borisenko I, Pleskachev Y Agrotechnical aspects of the development of soilprotective technologies(Transit). (2004).

36. Pazova $\mathrm{T}$ Technologies and means of mechanization for anti-erosion treatment of sloping soils of the Kabardino-Balkarian Republicp 32. (2009).

37. Tryapitsyn D.A. Justification of the parameters of the chisel working body with an upright tilted in the transverse vertical plane // Research and development of tillage and sowing machines. Tr. VISCOM. - M., -pp. 61-70. (1988).

38. Fayzullayev, Kh, Mamatov, S, Radjabov, M, Sharipov, Sh, Tavashov, R and Nurmanova, M. The quality of loosening the soil with subsoilers of the combined machine // IPICSE (2020). IOP Conf. Series: Materials Science and Engineering 1030 (2021) 012171.IOP Publishing. doi:10.1088/1757899X/1030/1/012171.

39. Temirov, I, Ravshanov, Kh, Fayzullaev, Kh, Ubaydullaev, Sh and Kodirov, U. Development of a machine for preparing the soil for sowing melons under the film // IPICSE (2020). IOP Conf. Series: Materials Science and Engineering 1030 (2021) 012169. IOP Publishing. doi:10.1088/1757-899X/1030/1/012169. 